\title{
Effect of Calcium Enriched Waste on Physicochemical Properties of Stabilized Subgrade Soil
}

\author{
Amit Kumar, D. K. Soni \\ Department of Civil Engineering, National Institute of Technology \\ Kurukshetra-136119, India \\ amit_6160040@nitkkr.ac.in; dksoni54@yahoo.com
}

\begin{abstract}
Generation of waste from the various industries causes harmful impact to environment if there has no safe management for their disposal or reuse. The construction industries have ability to reuse or utilize different types of solid wastes. The waste from poultry farms in the form of eggshell also cause problems to the environment and need some utilization. The eggshell powder (ESP) is enriched with natural lime; therefore, it can be used for soil stabilization. In the present paper, eggshell powder was used along with sodium chloride $(\mathrm{NaCl})$ and polypropylene fiber (PPF) to study their influence on physicochemical properties of soil. The soil samples were subjected to ten cycles of freeze-thaw before examining the $\mathrm{pH}$ of respective sample. Eggshell powder (3\%, $6 \%$ and $9 \%)$, sodium chloride $(2 \%, 4 \%$ and $6 \%)$ and polypropylene fiber $(0.05 \%, 0.1 \%$ and $0.15 \%)$ were used and design of experiments was developed using Taguchi technique. Results showed that inclusion of these materials had significant effect on the $\mathrm{pH}$ and unconfined compressive strength of subjected soil against harsh environmental conditions, although the relation between $\mathrm{pH}$ and UCS was found non-linear.
\end{abstract}

Keywords: Poultry waste, Stabilization, Taguchi technique, Optimization, Physicochemical, Freeze-thaw, Unconfined compressive strength.

\section{Introduction}

Fine grained soils are composed of crystalline and amorphous materials. Crystalline materials are responsible for the cohesive property of fine grained soils. Acidic nature of soil triggers the net negative charge in soil, that must be zero. So, the swaping ions starts by valency and termed as base exchange. The net negative charge that can be satisfied by commutable cations is called cation exchange capacity or base exchange capacity. This is a function of acidic or alkaline nature of water present in soil[1-2]. Electric charge of clay materials helps them to clump together. When quick lime reacts with clayey soil, that impart non plastic behaviour in the soil. As long as, the lime is present, $\mathrm{pH}$ reaches high and pozzolanic reactions commence; which in turn to age long strength[3-4]. During age long strength attainment, a high basicity created by lime that slow down the process of alumino silicates[5]. Plasticity characteristics of clayey soil and expansive soil was improved and deployed respectively after treating with lime and chloride. That was a function of inherent base exchange capacities of soils[6-7]. Lime mixing in clays prompts two reactions i.e. short term and long term reaction. During short term reaction exchangeable ions flocs and carbonation takes place. While agelong reaction produced pozzolanic and resistance type products[8-10]. Lime stabilization have benefits over other calcium based materials in terms of low or null emission of $\mathrm{CO}_{2}$ during production[11]. Lime-chloride-clay mixture was found a promising material for long term strength of road bed but this reaction ends up gradually. High content of salt may reverse the effects of biological matter present in ground[12-15]. Calcium sulphate $\left(\mathrm{CaSO}_{4} \cdot 2 \mathrm{H}_{2} \mathrm{O}\right)$ exposed to red clay and grey clay showed an improvement in compressive strength due to acceleration in pozzolanic reaction and found cheaper than other available material when used with lime and pozzolana[16]. While porous limestone produced reliable results at elevated temperature and facing to freeze-thaw cycles. The fabric of the porous limestone controlled the strength parameters[17]. Natural coir and sisal fibers improved stress bearing capacity and brittleness when mixed with chemicals namely sodium periodate, p-aminophenol and sodium hydroxide[18-19]. The solubility of silicates and aluminates increased the $\mathrm{pH}$ in media, which improved strength characteristics of clayey soil. A calcium-sodium-silicate gel is better for bond formation than a calcium-silicate gel[20-22]. While the lime and chloride based stabilization has been praised by many researchers but some oppose this theory totally. $\mathrm{NaCl}$ had spoiled the effects of lime 
in soil strengthening. High salt content also vanished the gain in UCS. High cation exchange capacity grasps high amount of calcium ions, those are key elements of cementitious products[23-25].

\section{Research significance}

Present study checks the feasibility of natural calcium based waste (eggshell powder) and sodium chloride to stabilize the fiber reinforced subgrade soil. An effort has been done to understand the chemistry behind strength improvement phenomenon by evaluating the physicochemical changes.

\section{Materials and Method}

To meet the goals of the present work, optimum moisture content (OMC) based; 21 days cured unconfined compressive strength (UCS) sized samples $(38 \mathrm{~mm}$ X $76 \mathrm{~mm})$ were prepared for freeze/thaw (FT) test. FT exposed each sample was subjected to UCS test. Deionized water was used to prepare the samples for $\mathrm{pH}$ test.

Soil was obtained by excavation of soil deposit at Srinagar, Jammu and Kashmir (India). The alienate materials like grass, leaves and pebbles etc. were extracted from the subjected soil to evade any biological content. The subjected soil was found of ML type as per plasticity chart proposed by Indian standard classification system (ISCS) and remaining index properties may listed as (G 2.6; LL 34\%; PL 29\%; PI 05; OMC 19.33\%; MDD $1.72 \mathrm{~g} / \mathrm{cc}$ and pH 0.77). Ground eggshell (pH 8.4) being a waste material and enriched with calcium was used as an additive and its typical chemical composition is $(\mathrm{CaO}$ 99.83\%; $\mathrm{Cl} 0.009 \% ; \mathrm{Al}_{2} \mathrm{O}_{3}, \mathrm{SiO} 2, \mathrm{MnO}$ and $\mathrm{CuO} 0.001 \%$ ) [26]. $\mathrm{NaCl}$; procured from a local chemical seller was in the state of transparent crystals. Polypropylene fibers (Triangular, $12 \mathrm{~mm}$ ) were used as reinforcing material.

Additives and their levels are tabulated in Table 1. MINITAB 17 oriented Taguchi's design of experiments in the form of Orthogonal Array (OA) is given in Table 2, in which, each column signifies level of factors and each row act for an experimental condition. A parent soil sample (R0) was also prepared along with OA. A comprehensive study of Taguchi technique can be done through Phadke (1989), Roy (2001) and Rahman (2008) [27-29].

Table 1: Additives at different levels.

\begin{tabular}{|c|c|c|c|}
\hline \multicolumn{3}{|c|}{ Additives } \\
\hline Level & ESP $(\%)$ & PPF $(\%)$ & $\mathrm{NaCl}(\%)$ \\
\hline 1 & 3 & 0.05 & 2 \\
\hline 2 & 6 & 0.1 & 4 \\
\hline 3 & 9 & 0.15 & 6 \\
\hline
\end{tabular}

Table 2: Experimental Design (Orthogonal Array).

\begin{tabular}{|c|c|c|c|}
\hline \multirow{2}{*}{ Mix Designation } & \multicolumn{2}{|c|}{ Additives } \\
\cline { 2 - 4 } & ESP (\%) & PPF (\%) & 2 \\
\hline R1 & 3 & 0.05 & 4 \\
\hline R2 & 3 & 0.10 & 6 \\
\hline R3 & 3 & 0.15 & 4 \\
\hline R4 & 6 & 0.05 & 2 \\
\hline R5 & 6 & 0.10 & 6 \\
\hline R7 & 6 & 0.15 & 2 \\
\hline R8 & 9 & 0.05 & 4 \\
\hline R9 & 9 & 0.10 & 0.15 \\
\hline
\end{tabular}




\section{Test Procedure}

Following the experimental protocol, the basic properties of the Himalayan soil i.e. specific gravity, plasticity characteristics, IS classification were determined in laboratory as per Indian standards code of soil testing. UCS based freezethaw applied (10 Cycles) samples were taken under physicochemical testing of plastic soil. Samples for $\mathrm{pH}$ test were prepared using the method as suggested in [30-31] which implicates mixing the solids with deionized water (1:5 :: solid:water), periodically agitating samples, and then testing with a multifunction $\mathrm{pH}$ meter; Orion 5 Star, Thermo Scientific (Fig. 1) confirming to IS:2720 (Part XXVI)-1987 after 1 hour.

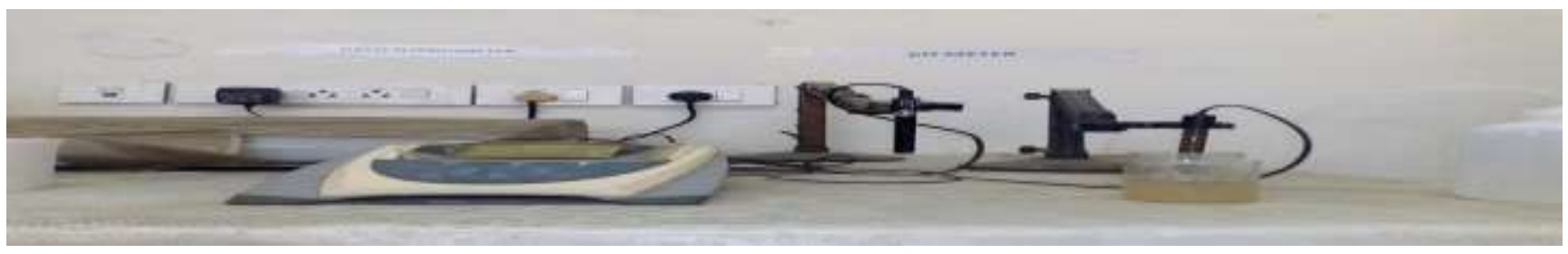

Fig. 1: pH Meter.

\section{Results and Discussion}

Among all positive and negative responses of lime and chloride stabilization in context of $\mathrm{pH}$ and UCS results, present work summarized an effort towards understanding the behaviour of plastic soil treated with poultry waste (ESP) and sodium chloride. Polypropylene fiber reacted as neutral. Fig. 2(a) and (b) shows the graphical representation of the pH and UCS results obtained in laboratory, respectively.

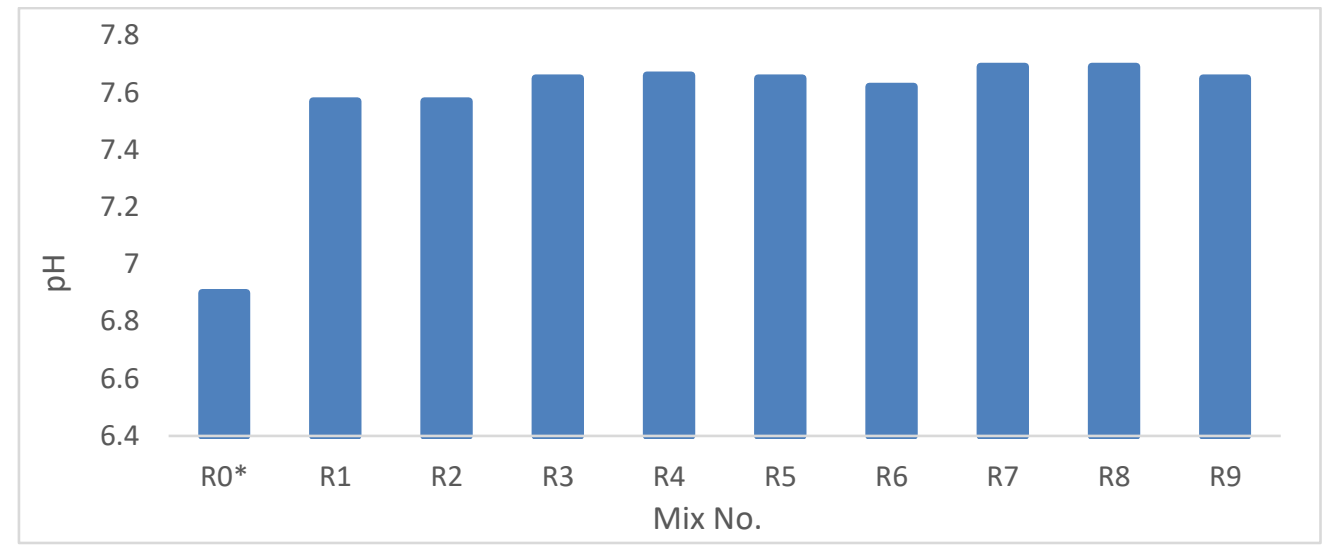




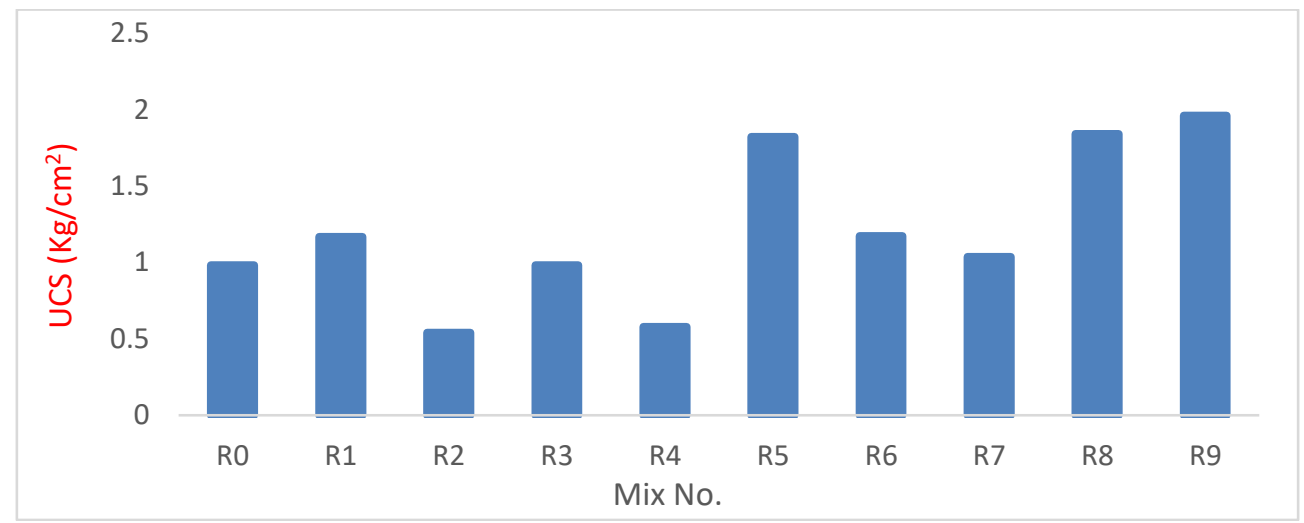

*Parent soil sample after $10 \mathrm{FT}$ cycles

(b)

Fig. 2: (a) Mix vs. pH and (b) Mix vs. UCS.

From Figs. 2(a) and 2(b), it can be seen that, there is no direct interdependency between $\mathrm{pH}$ and UCS of the subjected soil. Both parameters influenced independently without any interaction between them. Although the $\mathrm{pH}$ value of all specimens were higher than parent soil specimen but UCS produced insignificant results. The prime reason of the fluctuation in UCS value of each specimen is the nonlinearity in mix proportions as given by design of experiments. The mixes containing high chloride content tends to liquefy under moisture that is why they were of low compressive strength. Frequent freeze and thaw triggers the moisture content of soil and high moisture appetize the absorption capacity of fibers that ultimately results in variation in strength of soil under moisture. The same can be seen in figure 2 (b), where too high and low content of fibres were found fail to maintain the moisture around optimum quantity.

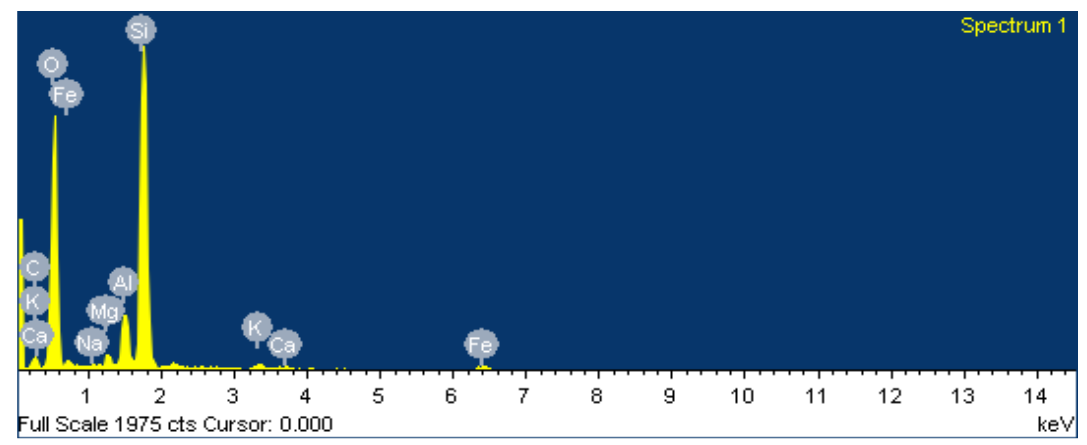

(a)

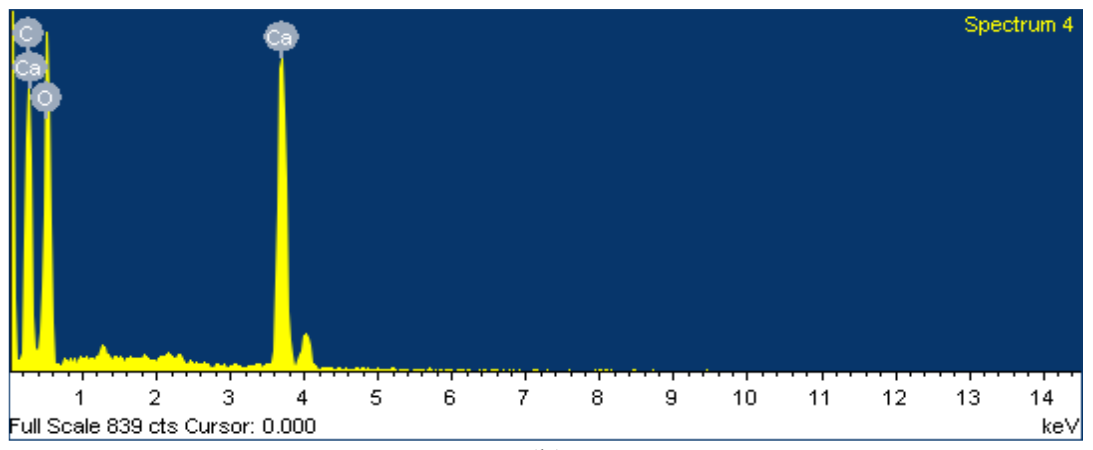

(b)

Fig. 3: Chemical spectrographs of (a) parent soil without FT cycles and (b) ESP. 
From spectrograph of parent soil (Fig. 3a), it can be seen that silica is available for the reaction and; alumina and other minerals are in traces. EPS spectrograph (Fig. 3b) showed high content of calcium, which is essential requirement for the pozzolanic reaction. Rapid cation exchange by the effect of eggshell powder is the main reason for the fluctuating behaviour of the soil matrix. Although lime-sodium has a long term strength attainment, same has been found in the present study. An exothermic reaction between lime content and soil minerals diminishes the pozzolanic effect and an agelong strength attainment starts. As soon as the lime content approaches initial consumption of lime (ICL), soil pH turns out to sufficiently high to make available soil silica and alumina soluble. Afterwards ICL, the residual calcium from lime starts to react with the available silica and alumina in the soil to initiate pozzolanic reactions. The pozzolanic reactions remain continue as long as high-pH environment and residual calcium are present in the soil and produces the product those helps to stabilize the soil [32].

\section{Conclusions}

An experimental study was performed to explore the effects of calcium enriched eggshells and sodium chloride on physicochemical and strength properties of polypropylene fibre reinforced fine grained soil. Following conclusions may summarize from the study:

1. Cation exchange capacity regulates the $\mathrm{pH}$ of the soil. Higher clay content in the soil leads to higher cation exchange capacity and higher $\mathrm{pH}$.

2. Solubility of silicates and aluminates of soil matrix may improve the strength characteristics.

3. Time dependent reactions regulate the strength improvement characteristics through pozzolanic and resistance reactions.

4. Prolong the presence of silica and calcium in soil matrix, continue the pozzolanic reaction.

Although, the present study showed results resembles to previous studies based on $\mathrm{pH}$ and unconfined compressive strength. But as many researchers have produced very straight results, so, it is suggested that, further studies should be done on clayey soil using different additives for more clarification and elaboration of results.

\section{Acknowledgements}

Authors wish to thanks to the Bridge Engineering and Structures Division (Central Road Research Institute, New Delhi) for their support to conduct the Freeze and Thaw test on soil. This research is financially supported by Council of Scientific and Industrial Research (CSIR), New Delhi (Acknowledgement No. 141099/2K17/1).

\section{References}

[1] B. C. Punmia, A. K. Jain, and A.K. Jain, Soil Mechanics and Foundations. New Delhi, India: Laxmi Publications (P) Ltd., 2005.

[2] K. R. Arora, Soil Mechanics and Foundation Engineering. Delhi, India: Standard Publishers Distributors, 2015.

[3] A. Roohbakhshan and B. Kalantari, "Influence of lime and waste stone powder on the pH values and atterberg limits of clayey soil," Annals of faculty engineering hunedoara - International Journal of Engineering, tome 11, vol. 178, no. 4, pp. 177-180, 2013.

[4] M. M. Bessaim, A. Bessaim, H. Missoum and K. Bendani, "Effect of quick lime on physicochemical properties of clay soil," CMSS 2017, MATEC, Web of Conferences, vol. 149, 2017.

[5] F. G. Bell, "Lime stabilization of clay minerals and soils," Engineering Geology, vol. 42, pp. 223-37, 1996.

[6] M. Hussain and S. K. Dash, "Influence of lime on plasticity behaviour of soils," Indian Geotechnical Conference, GEOtrendz, 2010.

[7] Zumrawi, M. E. Magdi and K. A. Eltayeb, "Laboratory investigation of expansive soil stabilized with calcium chloride," International Scholarly and Scientific Research \& Innovation, vol. 10, no. 2, pp. 223-227, 2016.

[8] M. R. Abdi and S. Wild, "Sulphate expansion of lime-stabilized kaolinite: I. Physical characteristics," Clay Mineralogy, vol. 28, no. 4, pp. 555-567, 1993. 
[9] S. Wild, J. Kinuthia, R. Robinson and I. Humphreys, "Effects of ground granulated blast furnace slag (GGBS) on the strength and swelling properties of lime-stabilized kaolinite in the presence of sulphates," Clay Mineralogy, vol. 31, no. 3, pp. 423-433, 1996.

[10] S. Boudaghpour and F. Majdzadeh, "Environmental effects of lime on mechanical characteristics of stabilized closedtexture soils," International Journal of Geology, vol. 8, pp. 60-64, 2014.

[11] I. T. Jawad, M. R. Taha, Z. H. Majeed and T. A. Khan, "Soil stabilization using lime: Advantages, disadvantages and proposing a potential alternative," Research Journal of Applied Sciences, Engineering and Technology, vol. 8, no. 4, pp. 510-520.

[12] C. S. Shon, D. Saylak and S. K. Mishra, "Combined use of calcium chloride and fly ash in road base stabilization," Journal of the Transportation Research Board, vol. 2186, pp. 120-129, 2010.

[13] L. K. Davidson, M. Dames, T. Demirel and R. L. Handy, "Soil pulverization and lime migration soil-lime stabilization," National Research Council, HRB Record, vol. 92, pp. 103-126, 1965.

[14] P. Azarfar and M. Abdi, "The effect of sodium chloride on compressive strength and plastic properties of kaolinite stabilized by lime," Proceedings of the 6th International Conference of Civil Engineering, University of Isfahan, 2003, pp. 305-312.

[15] K. Onitsuka, M. Chirdchanin, M. Kouno and T. Negami, "Effect of organic matter on lime and cement stabilized Ariake clays," Journal of Geotechnical Engineering, vol. 729, pp. 1-13, 2003.

[16] H. Gadouri, K. Harichane and M. Ghrici, "Effect of calcium sulphate on the geotechnical properties of stabilized clayey soils," Periodica Polytechnica Civil Engineering, vol. 61, no. 2, pp. 256-271, 2017.

[17] Z. Pápay and Á. Török, "Effect of thermal and freeze-thaw stress on the mechanical properties of porous limestone", Periodica Polytechnica Civil Engineering, vol. 62, no. 2, pp. 423-428, 2018.

[18] V. N. Khatri, R. K. Dutta, G. Venkataraman and R. Shrivastava, "Shear strength behaviour of clay reinforced with treated coir fibres," Periodica Polytechnica Civil Engineering, vol. 60, no. 2, pp. 135-143, 2016.

[19] S. Kumar, B. V. Tilak and R. K. Dutta, "Engineering properties of Bentonite-Lime-Phosphogypsum composite reinforced with treated sisal fibers," Periodica Polytechnica Civil Engineering, vol. 61, no. 3, pp.554-563, 2017.

[20] T. Abood, A. B. Kasa and Z. B. Chik, "Stabilization of silty clay soil using chloride compounds," Journal of Engineering Science and Technology, vol. 2, no. 1, pp.102-110, 2007.

[21] M. H. Davoudi and E. Kabir, "Interaction of lime and sodium chloride in a low plasticity fine grain soils," Journal of Applied Sciences, vol. 11, pp. 330-335, 2011.

[22] E. Kabir, "The effect of lime on uniaxial compressive strength of fine grain soils containing sodium chloride," M.Sc. Thesis, Faculty of Engineering, Department of Civil Engineering (In Persian).

[23] H. Tremblay, J. Duchesne, J. Locat and S. Leroueil, "Influence of the nature of organic compounds on fine soil stabilization with cement," Canadian Geotechnical Journal, vol. 39, pp. 535-546, 2002.

[24] D. Zhang, C. Z. F. Libina , L. Songyua and L. Weizheng, "Evaluation of the influence of salt concentration on cement stabilized clay by electrical resistivity measurement method," Engineering Geology, vol. 170, pp. 80-88, 2014.

[25] H. Yuan, X. Huanga, J. Ningb, B. Zhua and Y. Cheng, "Effect of cation exchange capacity of soil on stabilized soil strength," Soils and Foundations, vol. 54, no. 6, pp. 1236-1240, 2014.

[26] F. Adogla, P. P. K. Yalley and M. Arkoh, "Improving compressed laterite bricks using powdered eggshells," International Journal of Engineering and Science (IJES), vol. 5, no. 4, pp. 65-70, 2016.

[27] M. S. Phadke, Quality engineering using robust design. New Jersey, USA: Prentice-Hall, 1989.

[28] R. K. Roy, Design of experiments using the taguchi approach. New York, USA, Wiley Interscience, 2001.

[29] Z. Rahman and F. Talib, "A study of optimization of process by using Taguchi's parameter design approach," Icfai University Journal of Operations Management, vol. 7, no. 3, pp. 6-17, 2008.

[30] J. L. Eades and R. E. Grim, "A quick test to determine lime requirements for lime stabilization," Highway Research Record, vol. 139, no. 6172, 1966.

[31] A. Kumar and D. K. Soni, "Significance of pH in fine grained soil," ICSWMD 2018, Lecture Notes in Civil Engineering, vol. 21, pp. 264-272, 2019. 
[32] H. Singh, P. Garg and I. Kaur (Eds.) Proceedings of the $1^{\text {st }}$ International conference on sustainable waste management through design 2018, Lecture Notes in Civil Engineering, (C) Springer Nature America AG 2019. 